\section{Ethics and in-vitro fertilisation}

The technique of in-vitro fertilisation is well established. The programme at Monash University offers individual patients with tubal and idiopathic infertility a $15 \%-20 \%$ chance of becoming pregnant. The rate of success in oocyte collection is between $85 \%$ and $90 \%$, the rate of fertilisation is $80 \%-90 \%$, and embryo development is achieved in 50\%-70\% of cases. Similar success has been achieved in Cambridge in Britain and Norfolk, Virginia, USA. The ethical issues raised by these achievements were discussed earlier this year at a conference arranged by Monash University's Centre for Human Bioethics.

On the near horizon are the possibilities of preservation of human oocytes and embryos by freezing and the use of donor oocytes and embryos for infertile women. More contentious future developments include the use of surrogate mothers and deliberate selection of embryos of one sex in the case of specific sex-linked diseases such as haemophilia and muscular dystrophy.

Discussion of the fundamental ethical issues became polarised in two predictable directions. The traditional Roman Catholic view" regards in-vitro fertilisation as "immoral and absolutely unlawful" and rejects the right of man to intrude in this manner into the origin of human life. It holds that from the moment of fertilisation a new individual human being exists possessing an inviolable right to life and to protection from any manipulation which may threaten its integrity. The proponents of these attitudes repeatedly used the "Pandora's Box" argument, presenting the potential horrors of future developments-such as eugenic control of births, embryo splitting, cloning, genetic manipulations, and human-animal hybrids--to argue that in-vitro fertilisation should cease.

The alternative view is that ethics is independent of religious dogma or theology and is essentially a matter for rational argument and reasoned debate. The many religions and their different opinions about right and wrong make it difficult to sustain a claim that ethics depends on theology. "Is something good because the gods approve of it or do the gods approve it because it is good ?" asked Socrates, and his question was put forward in the debate as a profound issue needing an answer. If the gods approved of torture (as may have been assumed in the days of the Inquisition) then torture would be "good." To argue that torture is good makes morality arbitrary; yet to deny that torture is good presupposes the existence of ethical standards independent of approval or disapproval by the gods. Faced with such arguments many theists have accepted that moral and ethical problems are amenable to solution by rational methods.

Many of the objections raised to in-vitro fertilisation may be countered by rational argument showing that they are inconsistent, non-universal, and depend upon particular religious beliefs. For example, it has been argued that because the unborn child cannot give consent in-vitro fertilisation is wrong. But none of us consented to our own natural procreation; hence the issue of consent is irrelevant to the method of fertilisation. The view that in-vitro fertilisation leads to "killing" of innocent human beings may be countered by the argument that transferring the embryo to the mother's womb gives it the greatest possible chance of survival-which cannot be construed as a wrong.

So long as questions were restricted to the ethical aspects of the practice of in-vitro fertilisation but not to its possible wider consequences on society none were found unanswerable. The more difficult questions relate to future developments, and their importance should not be obscured by irrelevant arguments whether in-vitro fertilisation is "natural" or whether as yet unconceived children should consent to their own conception.

One of these real ethical questions that was debated concerned the allocation of scarce medical resources. A contrast was drawn with the resources available for renal dialysis. Nephrologists in some countries still face dilemmas-though dialysis is a proved method of treatment and the stark alternative is early death. Is the cost (in Australia) of $\$ 25000$ a patient a year on dialysis acceptable when cuts are being made in other parts of the health system? Britain has the lowest acceptance rate of dialysis in Western Europe, largely as a result of cost containment; even within Britain there are gross discrepancies in the availability of dialysis in different areas. ${ }^{2}$ Clearly this scarce resource is still allocated arbitrarily-despite the value of the treatment having been established for almost 20 years. In the light of this the allocation of funds for in-vitro fertilisation is likely to remain arbitrary in the foreseeable future.

An emotional presentation of successful in-vitro fertilisation as the most important event in the lives of an infertile couple was counterbalanced by an analysis of the fears, anxieties, hopes, and disappointments of others who have been less fortunate. Speakers described in lucid terms the grieving of those who finally remain childless after months or years of peaks and troughs in their expectations.

The medicolegal difficulties surrounding in-vitro fertilisation are immense. The issues include the risk of deformity or defect, the degree of this risk, and the rights of the child to claim compensation. Should compensation be considered in the case of in-vitro fertilisation when children with hereditary disease have no redress against parents who conceived them in the knowledge of a $50 \%$ chance of producing a child with a known defect? If the child conceived in vitro can claim compensation should the parents or the researchers bear this burden?

The legal personality begins only at birth, but in at least three cases courts have accepted that a child has a cause of action arising out of an injury caused by an event such as a transfusion to the mother many years before. The fact that the parents had been told that the procedure is a new one in which the clinician cannot guarantee safety is certainly a defence against an action by the parents-but not against an action by a child born disabled as a result of the clinician's action. This may be another branch of the law in which it may be cheaper to kill than to maim. The right of the parents to claim compensation for the death of a child depends upon the child being born alive: under present laws they could not claim against a negligent act such as dropping a dish containing an embryo.

Laws are slow to evolve and slow to change, but anticipation of the possible problems which may arise could defuse some of the potential legal conflicts in the area.

PrisCILLA KINCAID SMITH

Professor of Medicine,

University of Melbourne,

Victoria 3050,

Australia

1 " Address of His Holiness Pope Pius XII to the Second World Congress on Fertility and Sterility" as cited by Leroy Walters in Human In Vitro Fertilization-A Review of the Ethical Literature. Hastings Centre Report August 1979, p 25.

2 Anonymous. Ethics and the nephrologist. Lancet 1981 ;i:594-6. 